\title{
ESTIMATION OF WILD HERBIVORE DAMAGE TO FIELD CROPS IN THE CZECH REPUBLIC IN 2019
}

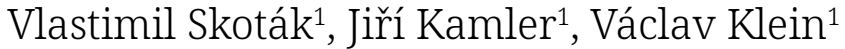 \\ ${ }^{1}$ Department of Forest Protection and Game Management, Faculty of Forestry and Wood Techology, Mendel \\ University in Brno, Zemědělská 1, 61300 Brno, Czech Republic
}

Link to this article: https://doi.org/10.11118/actaun.2021.041

Received: 20. 4. 2021, Accepted: 10. 6. 2021

To cite this article: SKOTÁK VLASTIMIL, KAMLER JIŘÍ, KLEIN VÁCLAV. 2021. Estimation of Wild Herbivore Damage to Field Crops in the Czech Republic in 2019. Acta Universitatis Agriculturae et Silviculturae Mendelianae Brunensis, 69(4): 467-472.

\begin{abstract}
Damage caused by free living herbivores to field crops has been a significant and long lasting, culminating problem which has not been solved yet. One of the reasons is missing methodologies and lack of precise data. The aim of our study was to estimate a total extent of damage caused by free living herbivores to field crops in the Czech Republic. We carried out a field research, determined the extent of the damage to main crops, and calculated the total extent of damage. Maize was the most damaged crop with a total of 8.8\% of damaged area followed by oat with $6.4 \%$. A significant gap occurred between awned and awnless wheat. While $6 \%$ of awnless wheat was damaged on average, it was only $1.5 \%$ for awned wheat. The least damaged crop was rape plant but due to its large sowing area and a relatively high market value, the loss cannot be considered low. The damage were affected by the distance of field from forests. Awned cereals seem to be suitable crops for places with a higher potential risk of damage. We estimated the damage in the Czech Republic in 2019 as high as 58433 thousand EUR.
\end{abstract}

Keywords: crop, Czech Republic, damage, game, quantification

\section{INTRODUCTION}

Free living herbovires are a valuable part of ecosystems and many species succeeded in adapting to landscape changes and form viable populations. Some animal species have their economic value and they are subject to farming. On the other hand, the existence of large herbovires is globally connected to significant economic losses due to the damage to field crops (Cappa et al., 2019; Kovács et al., 2019). The importance of this damage is subject to fluctuation depending mainly on animal species with their habitats in the vicinity of fields and their numbers, but also on other factors such as the structure of grown crops, value of agricultural production, landscape diversity and a supply of alternative food (Bleier et al., 2012; Matthews, 2019). The damage caused by free living herbivores to agriculture in the Czech Republic is also substantial and hardly any progress in this field has been made in the last decades. A dramatic decrease in once plentiful smaller species found in fields, such as hare or partridge, has been monitored. Simultaneously, numbers of ungulates have been consistently rising (Spitzer et al., 2020; Valente et al., 2020). They mostly need enough shelter and use field crops only transiently, but they still have a potential to completely damage covers of attractive crops on large areas and the damage caused by them can cause crucial economic losses for farmers. There are more reasons why despite the efforts made the extent of damage has not decreased - from the current state of legislation, the willingness of farmers to suffer decrease of harvest to changing environmental factors. What we consider a crucial influence is a non-existence of applicable methodologies for damage estimation 
and a missing damage database which would show the development of damage extent in time and its regional differences (Tsukada et al., 2013). These gaps in the data on damage lead to never-ending discussions and therefore hardly any progress is made.

Previous experience shows that it is challenging to determine the damage to field crops caused by animals even on individual, relatively small areas, let alone the larger ones (Michez et al., 2016; Kuželka and Surový, 2018). If a simple and reliable method existed, it would be intensively used and any attempts to estimate damage to larger areas would solve a compromise between information ability of the obtained data and labour intensity or probability of their obtainment. Taking into consideration the importance of the damage and its increasing tendency, it is necessary to look for the ways how to fill in the existing information gaps. Therefore, there has been an ongoing effort to improve methodology and also to quantify damage in the fields on larger areas. If an extent of damage for whole regions is to be determined, we can only speak about rough estimates. For example, Bleier et al. (2017) state that the annual damage to field crops caused by ungulates exceeds billions in USD. We can also find individual studies with main focus on smaller areas or a single animal species. To give an example, Trdan and Vidrih (2008) state that red deer causes a decrease in the grassland crops in Slovenia by 50\%. The estimated maize production losses in the north of Italy in the Pian di Spagna Protected Area exceeds 20000 EUR per farm per year (Corgatelli et al., 2019). Menichetti (2019) states that the damage caused by fallow deer in the southwest of Sweden is $375 \pm 196$ EUR per ha of wheat and $152 \pm 138$ EUR per ha of oat. Another source of information is compensation programmes which help farmers with a compensation for their damaged crops. The numbers only provide compensation amounts and do not reflect the total extent of damage. Furthermore, they do not include claims made by land owners to subjects with animal production. Only to give you an idea, Ravenelle and Nyhus (2017) state that approximately 140 million USD have been provided as a humanwildlife conflict compensation.

Even in the Czech Republic we do not have detailed information on the extent of field crops damage caused by free living animals. A lot of damage is not included into the assessment at all and even the assessed cases, when an owner asks for a compensation, have no central registration. Any older data on the extent of damage in the Czech Republic do not provide adequate reliability. For this reason, we made an attempt to estimate the extent of damage caused by free living animals to field crops for the whole Czech Republic based on inventorying of model areas.

\section{MATERIALS AND METHODS}

\section{Monitored Crops and Area Localization}

We collected data on field crops damage caused by animals in 2019 for wheat, maize, oat and rape plant. We distinguished between awned and awnless wheat and silage and grain maize.

Localities for the research were randomly chosen within the Czech Republic. Namely in the Bouzov, Blansko, Brno, Znojmo, Netolice, Prachatice, České Budějovice, Klatovy, Tišnov and Pelhřimov regions. For each locality a random choice of areas with monitored crops was made.

\section{Data Collection and Their Assessment}

Every assessed area sown with one type of crop was divided into three zones depending on the distance from edges. The first zone includes the first belt within 0-30 $\mathrm{m}$ from the edge of the cover, the second belt within 31-60 $\mathrm{m}$ from the edge of the cover and the rest within a distance of more than $61 \mathrm{~m}$ belongs to the third belt. Such marked out zones were systematically scanned through and we recorded the damage extent to individual inventory areas. These were square-shaped. Each with an area of $25 \mathrm{~m}^{2}$. There were 15 of them in each zone and they were evenly located all over the area.

We also recorded the distance from forest complexes for each individual field. Uninterrupted forest covers with a minimal area of 20 ha, which provide a permanent shelter for ungulate animals, are considered a forest complex. Three zones (0-200 m, 201-400 m a 401 + m) of field crop areas were determined for the complexes. At the same time we tried to make sure the monitored fields covered the widest possible distance range from forest.

\section{The Damage Estimation for the Czech Republic}

Our own data on the damage of individually assessed field crops formed a base for the quantification of the damage extent. The damage to rye and triticale was estimated using the degree of damage to wheat. Other necessary data were found in public databases. We found out sowing areas of the assessed crops in the Czech Statistical Office data and used a 10-year average for 2008-2018 for our calculation. We also worked with an average size and shape of fields. An average field has an area of 20 ha and its average shape is a rectangle with sides ranging from 1:2 to 1:4. It is best represented by a rectangle with sides $634 \times 317 \mathrm{~m}$. From these data we calculated proportions of individual zones for an average field (Tab. I). We counted the damage in these individual zones.

Another input was an average yield of monitored crops and an average realized price (Tab. II). For yields, we used an average of the data from the Czech Statistical Office for the 10-year period (2008-2018) and a monthly average price for the year 2019 was used for prices. 
I: Average field area within individual zones for 2019

\begin{tabular}{cccccc}
\hline & Area of individual zone (\%) & & \multicolumn{3}{c}{ Area of individual zone $\left(\mathrm{m}^{2}\right)$} \\
\hline $0-30 \mathrm{~m}$ & $31-60 \mathrm{~m}$ & $61+\mathrm{m}$ & $0-30 \mathrm{~m}$ & $31-60 \mathrm{~m}$ & $61+\mathrm{m}$ \\
\hline 13.7 & 12 & 74.3 & 27534 & 24117 & 149327 \\
\hline
\end{tabular}

II: Average price, yield and area for 2008-2018 as per individual crop

\begin{tabular}{|c|c|c|c|}
\hline Crop & Average price (EUR per t) & Average yield (t per ha) & Average area (thousand ha) \\
\hline Wheat & 179.74 & 5.65 & 830 \\
\hline Rye & 172.07 & 4.75 & 29 \\
\hline Barley & 185.24 & 4.88 & 375 \\
\hline Oat & 158.04 & 3.36 & 45 \\
\hline Triticale & 171.95 & 4.07 & 54 \\
\hline Rape & 360.93 & 3.19 & 384 \\
\hline Grain maize & 165.84 & 7.53 & 99 \\
\hline Silage maize & 28.98 & 36.04 & 210 \\
\hline
\end{tabular}

Statistical analysis was performed in SPSS. We obtained the extent of damage to awned and awnless using the Kruskal-Wallis test, the correlation of the damage to awns using the Mann-Whitney test and for the correlation of the damage with the distance from forest the Spearman test was used.

\section{RESULTS}

\section{The Extent of the Damage as per Individual Crop}

Data on the damage to individual crops were collected on 141 fields. The most damaged crop was maize with a damage of $8.8 \%$ of its total area followed by oat with 6.4\%. Statistical difference occurred in awned and awnless wheat
(Mann-Whitney $\mathrm{P}=0.001$ ). On average 6\% of awnless wheat was damaged by animals whereas for awned wheat it was only 1.5\%. In general, awnless cereals suffer more damage than awned ones. The least damaged crop was rape plant with the $0.8 \%$ damage (Fig. 1 ).

\section{The Influence of the Distance from the Field Edge}

Damage of most crops depended on the distance from the field edge (Fig. 1). The damage to densely sown cereals was the biggest in the belt at the edge of the cover and it had a decreasing tendency with an increasing distance from the edge (Kruskal-Wallis, $\mathrm{P}<0.001$ ). On the contrary, the damage of maize was consistent no matter how far it was from the edge (Kruskal-Wallis, $\mathrm{P}=0.263$ ).

Extent of the damage (\%)

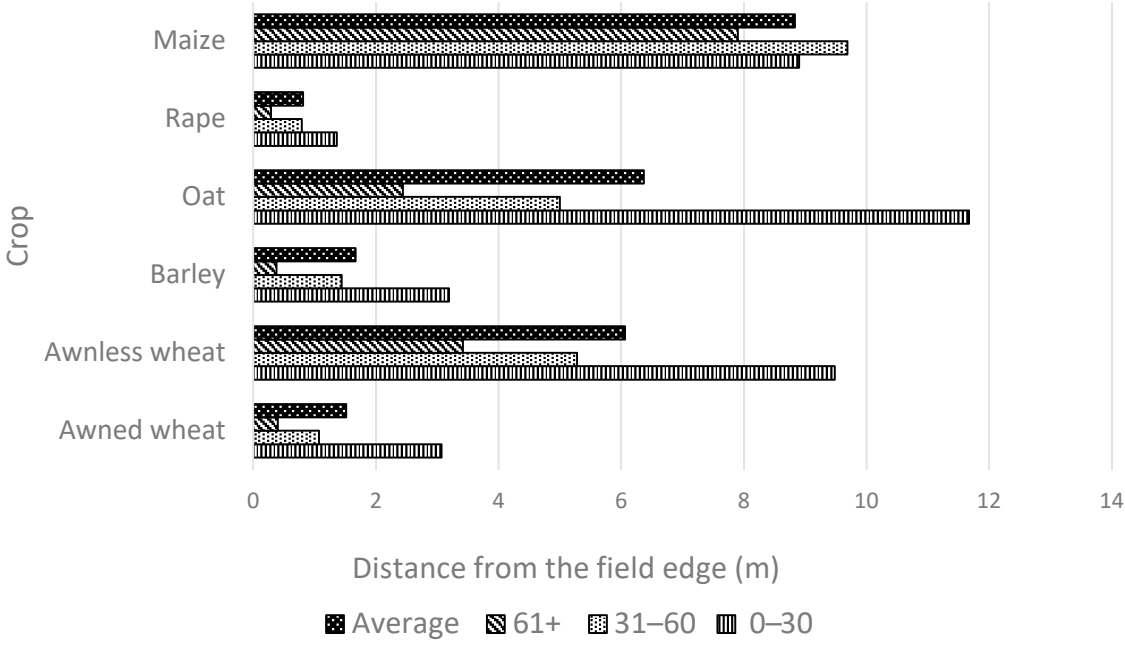

1: Extent of individual crop damage as per distance from field edge in 2019 


\section{The Influence of the Distance from the Forest Edge}

An average distance of an assessed field was 232 metres from the nearest forest (Fig. 2). This value is higher only in case of maize (319 metres). Densely sown cereals and rape plant were sown closer to the forest edge and awned cereals were closer than awnless ones. Areas with oat were the closest to forest covers (on average 88 metres from forest covers).

\section{The Damage Estimation for Individual Crops}

We calculated an area of individual zones from the edge of the covers for each assessed crop. Based on the data on the extent of damage, average price and average yield, we estimated a financial loss for individual crops for the whole Czech Republic (Tab. III).

The average loss per hectare for grain maize was the highest totalling at 103 EUR per hectare. It was followed by silage maize (86 EUR per hectare). By contrast, the lowest losses were calculated for rape plant and barley. The average loss per hectare of agricultural area (2 082079 ha) was 28 EUR.
The extent of damage to awned and awnless wheat was different, therefore we used an average value for further calculations. When recalculated for the total sowing area, the damage totalled at 22071 ha, which amounts to 22415 thousand EUR. The extent of barley damage was several times lower than the extent of wheat damage. When recalculated for the total sowing area, the damage totalled at 3346 ha, which amounts to 3024 thousand EUR. After calculating the damage for all individual crops and adding rye and triticale, the total field crops animal damage estimation in the Czech Republic amounted to 58433 thousand EUR.

\section{DISCUSSION}

While making an inventory, we went through 143 fields and made an assessment of the damage for 6435 smaller areas. The total area of assessed fields was approximately 1231 hectares. This makes $0.06 \%$ of the average annual area sown by monitored crops. To make a comparison, an inventory of the forest cover damage caused by animals in the Czech Republic in 2015 was made on 5182 hectares, which makes $0.2 \%$ of farmland area.

\section{Average distance of fields from forest $(\mathrm{m})$}

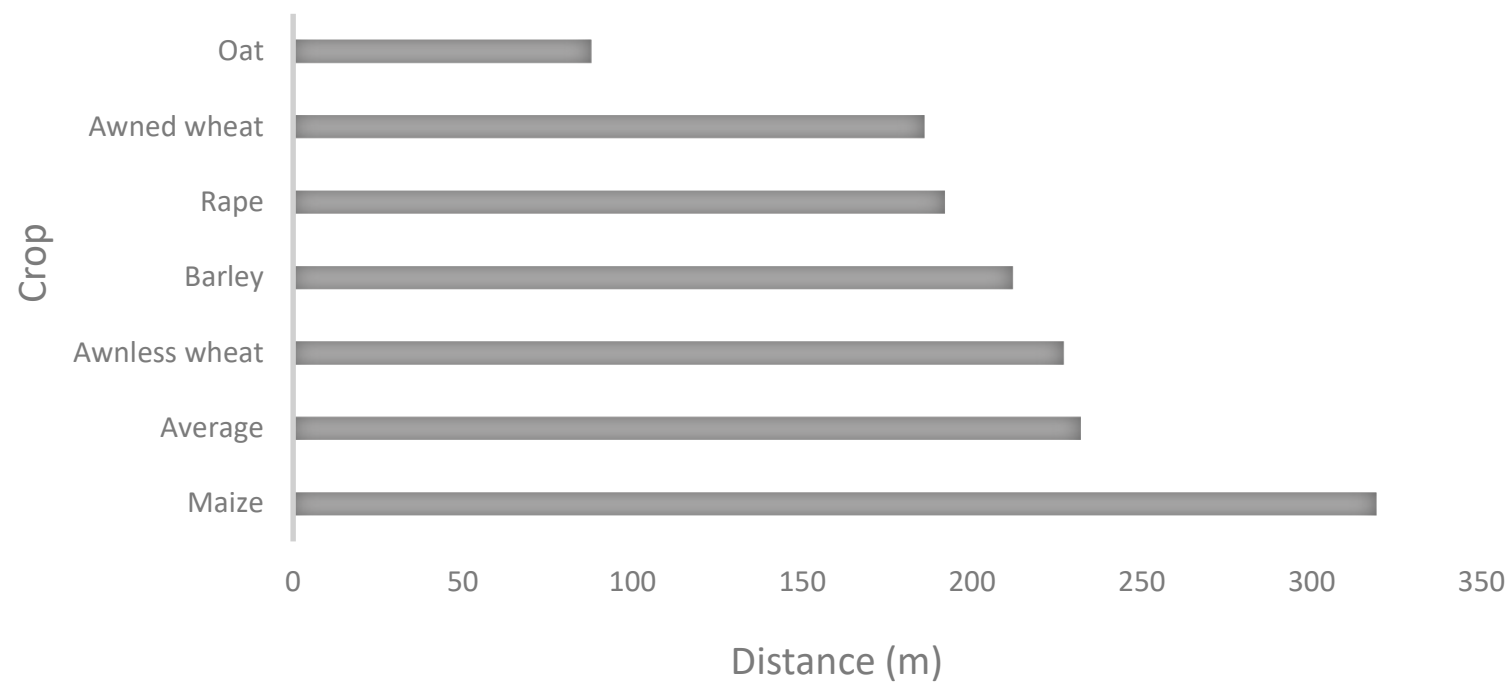

2: Average distance of fields from forest in 2019

III: Production loss caused by animals in 2019 as per individual crop

\begin{tabular}{|c|c|c|c|}
\hline Crop & Damage in CZ (thousand ha) & Damage in CZ (EUR/ha) & Damage in CZ (thousand EUR) \\
\hline Wheat & 22.07 & 27.00 & 22415 \\
\hline Barley & 3.35 & 8.06 & 3024 \\
\hline Oat & 1.82 & 21.30 & 968 \\
\hline Rape & 1.91 & 5.72 & 2198 \\
\hline Grain maize & 8.20 & 103.04 & 10234 \\
\hline Silage maize & 17.31 & 86.19 & 18082 \\
\hline
\end{tabular}


However, habitat conditions of tree species show higher heterogeneity than in case of cultivated farmland.

Undoubtedly, the existence of shelter is one of the prerequisites of the appearance of big ungulates which play a decisive role in the damages. Fields located on places further away from forest complexes or separated by natural or human-made barriers (rivers or motorways) will suffer a minimal damage. Bleier et al. (2017) state that 70-90\% of the damage occurs within 300 metres from forest edge. Cozzi et al. (2019) found out a 97\% concentration of risk zones within 400 metres from the most suitable sites. Contrary to other authors (Lemel, 1999), taking into account average values, we did not find out a significant influence of the distance of a forest complex, which will probably be mostly related to the structure of our landscape and also an ability of bigger animals to migrate to get some food and shelter reaching even further sites because forest complexes and their surroundings are burdened by tourism during the vegetation period. Paradoxically, animals can feel more secure in vast fields providing shelter (Cahill et al., 2003).

Crop preference turned out to be a more important factor than the distance from forest. We detected that the most severe damage in per cent was in maize which reflects a high attractivity of this crop especially for wild boar (Bleier et al., 2017). The summary shows that maize was the furthest from forest but at the same time it was the most damaged crop. On top of that, the damage did not reach the highest values on edges, as in case of other crops, but it is evenly spread out throught the whole stand with no correlation to the distance from the field edge. This reflects behaviour of animals which feel secure in higher maize stands and therefore it goes further away from dangerous edge first and only then it starts to get food. Or it can dwell here permanently and does not have to leave high and vast stands except when searching for water sources. We found out a significant influence of the distance of the field from the nearest forest complex
(Spearman $\mathrm{P}<0.001)$. This is probably related to a high attractivity of maize fields which, if located within an acceptable distance, strongly attract all herbivore animal species because of both food and shelter (Flores-Armillas et al., 2020). Another aspect which supports damage to grain maize is a very late harvest. While maize fields are not harvested yet, other crops were harvested long before, which leads to the concentration of animals on them. High damage values in oat and awnless wheat reflect high nutritional attractivity of these crops (Schley et al., 2008). On the other hand, awned cereals on average were the closest to forest and they suffered the least damage. Therefore, we can conclude that awned wheat is the least attractive for animals. Just as Kristiansson (1985) and Schley and Roper (2003), we detected a significant damage due to rolling by wild boar which mostly in cereals caused higher damage than the consumption itself.

An estimate of total damage was determined for the mentioned crops. By adding up the values we obtained an annual damage of 58433 thousand EUR caused by animals on field crops. The most severe damage occurred in maize and wheat which is related to their significant sowing areas and a large extent of damage. The total estimate of the damage caused by animals is certainly an estimate based on a limited aggregate of data which cannot fully represent important factors which can have an impact on the damage extent caused by animals. These factors include the structure of landscape, crop types, animal species and their numbers in individual regions and others. Crops of a lesser importance were not included but they also suffer damage. For example sunflower, potatoes and others. If a larger inventory had been made, the obtained data would provide a higher accuracy and it would most probably lead to a small increase in the total damage. Yet, we think the differences would not be substantial. With respect to the fact that there are no similar data on the estimate of the damage in the Czech Republic available, we consider these results contributive.

\section{CONCLUSION}

The study was focused on the intensity of field crop damage caused by animals and did not deal with factors which have a strong local impact on animal occurrence on a specific area. The detected annual damage to field crops totalling at 58433 thousand EUR is quite significant. The loss per hectare of agricultural area was 28 EUR. The biggest share in this number belongs to areas with maize (loss 103 EUR per hectare) which is very attractive for animals, mainly for wild boars. The detected damage extent is alarming and it is important for farmers to regularly monitor and reduce the damage by taking suitable agronomical measures. A substantial improvement of the whole situation could be brought by keeping a record of the damage extent, simplifying and unifying the methodology for its quantification. The data obtained in this way would enable to monitor the development of damage in time and it would be usable even for subjects running businesses with animals.

\section{REFERENCES}

BLEIER, N., LEHOCZKI, R., ÚJVÁRY, D. et al. 2012. Relationships between wild ungulates density and crop damage in Hungary. Acta Theriologica, 57(4): 351-359. 
BLEIER, N., KOVÁCS, I., SCHALLY, G. et al. 2017. Spatial and temporal characteristics of the damage caused by wild ungulates in maize (Zea mays L.) crops. International journal of pest management, 63(1): 92-100.

CAHILL, S., LLIMONA, F. and GRÀCIA, J. 2003. Spacing and nocturnal activity of wild boar Sus scrofa in a Mediterranean metropolitan park. Wildlife Biology, 9(4): 3-13.

CAPPA, F., LOMBARDINI, M. and MERIGGI, A. 2019. Influence of seasonality, environmental and anthropic factors on crop damage by wild boar Sus scrofa. Folia Zoologica, 68(4): 47-54.

CORGATELLI, G., MATTIELLO, S., COLOMBINI, S. et al. 2019. Impact of red deer (Cervus elaphus) on forage crops in a protected area. Agricultural Systems, 169: 41-48.

COZZI, M., PRETE, C., VICCARO, M. et al. 2019. Impacts of wildlife on agriculture: A spatial-based analysis and economic assessment for reducing damage. Natural Resources Research, 28(1): 15-29.

FLORES-ARMILLAS, V. H., LÓPEZ-MEDELLÍN, X., GARCÍA BARRIOS, R. et al. 2020. Landscape Features Associated with Damage to Maize (Zea mays) Fields in Central México: A Comparison of Wind and Wildlife Damage. Agriculture, 10(10): 460.

KUŽELKA, K. and SUROVÝ, P. 2018. Automatic detection and quantification of wild game crop damage using an unmanned aerial vehicle (UAV) equipped with an optical sensor payload: a case study in wheat. European Journal of Remote Sensing, 51(1): 241-250.

KOVÁCS, I., SZABÓ, A., SCHALLY, G. et al. 2019. Analysis of game damage estimation methods in winter wheat (Triticum aestivum) thruogh GIS simulations. Review on Agriculture and Rural Development, 8(1-2): 41-46.

KRISTIANSSON, H. 1985. Crop damage by wild boars in Central Sweden. In: Proceedings of the XVII ${ }^{\text {th }}$ Congress of the International Union of Game Biologists. Brussels, Belgium: IUGB, pp. 605-609.

LEMEL, J. 1999. Populationstillväxt, dynamik och spridning hos vildsvinet, Sus scrofa, i mellersta Sverige: slutrapport. Svenska Jägareförbundet.

MATTHEWS, J. A. 2019. Quantifying White-tailed Deer Density and Its Impacts on Agricultural Systems. Master's Thesis. Department Forestry and Natural Resources. University of Kentucky.

MENICHETTI, L., TOUZOT, L., ELOFSSON, K. et al. 2019. Interactions between a population of fallow deer (Dama dama), humans and crops in a managed composite temperate landscape in southern Sweden: Conflict or opportunity? PloS One, 14(4): e0215594.

MICHEZ, A., MORELLE, K., LEHAIRE, F. et al. 2016. Use of unmanned aerial system to assess wildlife (Sus scrofa) damage to crops (Zea mays). Journal of Unmanned Vehicle Systems, 4(4): 266-275.

RAVENELLE, J. and NYHUS, P. J. 2017. Global patterns and trends in human-wildlife conflict compensation. Conservation Biology, 31(6): 1247-1256.

SCHLEY, L. and ROPER, T. J. 2003. Diet of wild boar Sus scrofa in Western Europe, with particular reference to consumption of agricultural crops. Mammal review, 33(1): 43-56.

SCHLEY, L., DUFRÊNE, M., KRIER, A. et al. 2008. Patterns of crop damage by wild boar (Sus scrofa) in Luxembourg over a 10-year period. European Journal of Wildlife Research, 54(4): 589.

SPITZER, R., FELTON, A., LANDMAN, M. et al. 2020. Fifty years of European ungulate dietary studies: a synthesis. Oikos.

TRDAN, S. and VIDRIH, M. 2008. Quantifying the damage of red deer (Cervus elaphus) grazing on grassland production in southeastern Slovenia. European Journal of Wildlife Research, 54(1): 138-141.

TSUKADA, H., KIDA, T., KITAGAWA, M. et al. 2013. Simple quantitative method for estimation of herbage damage caused by sika deer (Cervus nippon). Grassland Science, 59(3): 146-155.

VALENTE, A. M., ACEVEDO, P., FIGUEIREDO, A. M. et al. 2020. Overabundant wild ungulate populations in Europe: management with consideration of socio-ecological consequences. Mammal Review, 50(4): 353-366. 